\title{
The Effect of Cervical Stabilizing Exercises in the Standing Position and the Supine Position on Deep Neck Muscle Strength and Endurance
}

\author{
Jinyeol Jeon, PhD ${ }^{1)}$, Sungbum Ju, PhD ${ }^{2)}$, Hyunja Jeong, PhD ${ }^{3)}$ \\ 1) Department of Sports Science, Daegu Catholic Uiversity \\ 2) Major in Excercise Therapy, Department of Health \& Physical Education, Kochi University: 2-5-1, \\ Akebono-cho, Kochi, 780-8520 Japan. \\ TEL: +81 88-844-8391,FAX: +8188-844-8391,E-mail: accent-ju@daum.net \\ 3) Department of Dental Hygiene, Daegu Health College
}

\begin{abstract}
Purpose] The purpose of this study was to clarify the effect of cervical stabilizing exercises in the standing position and the supine position on the strength and endurance of deep neck muscles (DNM). [Subjects] Twenty subjects performed cervical stabilizing exercises in the standing position (standing group) and 20 subjects performed cervical stabilizing exercises in the supine position (supine group). [Methods] The subjects did cervical stabilizing exercises in the standing or the supine position three times a week for a total of six weeks. Before and after the experiment, strength and endurance were measured. [Results] Both the standing group and the supine group showed increased strength and endurance after the intervention. However, there was no significant difference in the strength and endurance of the two groups before or after the intervention, or in the pre-post intervention differences. [Conclusion] For cervical strength and endurance improvement, treatment is generally given in the supine position. However, the exercise in the standing position was also effective. Therefore, if there are spatial or equipment limitations, the exercise in the standing position should be taught as an exercise method for the home or office.

Key words: Cervical stabilizing exercise, Standing position, Supine position
\end{abstract}

(This article was submitted Nov. 10, 2011, and was accepted Dec. 24, 2011)

\section{INTRODUCTION}

Although the pathological causes of neck disorders are not clear revealed, muscle fatigue generated by maintaining muscular contraction to fix head posture in different positions is known as one of the causes of chronic cervical pain ${ }^{1}$, 2). Among recent therapeutic exercises, there is increasing interest in, understanding the effect of cervical stabilizing exercise, not only to prevent neck disorders, but also to reduce chronic cervical pain. These exercises induce cervical vertebra to maintain a neutral position by strengthening the deep muscles, such as the longus colli and the longus capitis, that play a major role in maintaining spinal stability. Patients with cervical pain show reduced strength and endurance in deep muscles, as well as a reduced ability to retract the lower jaw compared to normal people, according to many studies. Moreover, there is a report that stabilizing exercise is very effective at reducing chronic cervical pain and improving neck function ${ }^{3)}$. It is also reported that exercise has great impact on the strength and endurance of deep muscles ${ }^{4)}$. Among the widely known methods, there is a method that uses a sling ${ }^{5)}$ and a cervical flexion exercise in the supine position ${ }^{6}$, and a method that uses a pressure biofeedback unit $(\mathrm{PBU})^{7)}$. However, these methods require equipment and a room to lie down in, which is difficult for students or office workers who lack space. Despite this difficulty, there is no adequate study on an easier cervical exercise method that can be performed in a standing position. Therefore, the purpose of this study was to compare the effect of a cervical stabilizing exercise in the standing position, which is easier and convenient, with that of an exercise performed in the supine position, which is generally used.

\section{SUBJECTS AND METHODS}

From among 230 normal male and female students attending $\mathrm{G}$ College in $\mathrm{G}$ city, we chose 40 students who were clearly seen to have forward head posture. They were randomly divided into a standing group of 20 (10 males and 10 females), and a supine group of 20 (10 males and 10 females). This study excluded subjects who had problems in their muscular, skeletal, or nervous systems, those who had undergone cervical vertebra surgery, those with systemic diseases, or those with neck pain that accompanied a fracture. The study subjects were informed about the purpose and procedures of this study and agreed to participate voluntarily. The standing group had an average age of $23.1 \pm 1.4$ years, an average height of $166.3 \pm 7.8 \mathrm{~cm}$, and an average weight of $63.8 \pm 12.5 \mathrm{~kg}$, while the supine group had an average age of $23.7 \pm 1.8$ years, an average height of $166.8 \pm 8.9 \mathrm{~cm}$, and an average weight of $62.1 \pm 9.9 \mathrm{~kg}$. Gender was analyzed by the Chi-square test and age, height, and weight were analyzed 
Table 1. Comparison of strength and endurance before and after intervention in each group

$($ mean $\pm \mathrm{SD})$

\begin{tabular}{llcc}
\hline Category & & Pre intervention & Post intervention \\
\hline \multirow{2}{*}{ Strength } & standing group* & $10.1 \pm 4.6$ & $22.3 \pm 8.5$ \\
& supine group* & $10.3 \pm 8.2$ & $18.75 \pm 4.3$ \\
\multirow{2}{*}{ Endurance } & standing group* & $40.5 \pm 23.7$ & $57.4 \pm 25.3$ \\
& supine group* & $42.8 \pm 32.3$ & $61.5 \pm 23.3$ \\
\hline$* \mathrm{p}<0.05$ & & & (unit: sec)
\end{tabular}

Table 2. Comparison of strength and endurance between the experiment

\begin{tabular}{llcc}
\multicolumn{2}{c}{ group and the control group } & & (mean \pm SD) \\
\hline Category & & Standing group & Supine group \\
\hline \multirow{2}{*}{ Pre intervention } & strength & $10.1 \pm 4.6$ & $10.3 \pm 8.2$ \\
& endurance & $40.5 \pm 23.7$ & $42.8 \pm 32.3$ \\
\multirow{4}{*}{ Post intervention } & strength & $22.3 \pm 8.5$ & $18.75 \pm 4.3$ \\
& endurance & $57.4 \pm 25.3$ & $61.5 \pm 23.3$ \\
Difference & strength & $12.2 \pm 10.6$ & $8.4 \pm 6.4$ \\
& endurance & $16.9 \pm 18.3$ & $18.7 \pm 27.2$ \\
\hline
\end{tabular}

difference: post- intervention value - pre- intervention value (unit: sec)

by the independent t-test. Since there were no statistically significant differences $(p>0.05)$, we assumed that the two groups were homogeneous.

The cervical stabilizing exercise in the standing position was a modified version of a chin tuck that Wright et al. ${ }^{8)}$ suggested for correcting cervical position. This exercise involves leaning against a wall and maintaining a normal curve of the waist and pelvic area, placing a 5-mm thick notebook or book behind the head, and tucking the chin while maintaining the book against the wall with the whole head. The therapist varies the thickness of the book according to individual differences and prevents the patient from using superficial muscles, such as the upper trapezius, semispinalis capitis, and sternocleidomastoideus (SCM). The exercise was performed in five sets. Each set lasted for five minutes with a one-minute break between the sets. As the intervention progresses, static strength and muscle endurance increase, and the therapist increases the weight and resistance by increasing the thickness of the book. For the cervical stabilizing exercise in the supine position, subjects lay on a bed and bent their hip and knee joints to remove lumbar lordosis. The therapist put a PBU behind the neck and asked the subjects to push with maximum voluntary contractile strength (MVCS) and maintain the pressure at $\pm 2 \mathrm{mmHg}$ by using only deep muscles for strength training. The subjects were then asked to maintain a pressure of $80 \mathrm{mmHg}$ pressure between MVCS, within a \pm 2 $\mathrm{mmHg}$ range for endurance training. Each set lasted for five minutes, and five sets were performed with a one-minute break between sets ${ }^{4}$. Both the standing group and the supine group exercises were performed three times a week for six weeks and therapists who had over 10 years of experience conducted the exercises.

strength and endurance of the DNM were measured by revising the cranio-cervical flexion test (CCFT). The length of time that a patient can maintain MVCS is measured for atrength. The length of time that a patient can maintain base pressure between MVCS is measured for endurance. The revised CCFT used a PBU (Chattanooga Group, Australia) and was performed by three examiners. The PBU was placed behind the neck with the subjects in supine position. The base pressure was set at $80 \mathrm{mmHg}$ and the subject was asked to tuck his or her chin and push his or her head back against the bed. Examiner 1 observed the pressure guage. Examiner 2 checked the subject's posture for chin position for static muscle contraction of the cervical spine, while checking SCM contraction using the index and middle fingers. Examiner 3 timed the sets using a stopwatch. The time period of strength and endurance was checked whenever the subject lifted his or her chin, the SCM released contraction, or the pressure guage showed a more than $\pm 2 \mathrm{mmHg}$ change. The times of strength and endurance were measured both before and after the exercise intervention.

The experimental results were statistically analyzed using SPSS 12.0 KO (SPSS, Chicago, IL, USA). After the general characteristics of the subjects were determined, the paired t-test was used to compare pre- and post-intervention strength and endurance in each group. Differences between the two groups were tested using the independent t-test. The level of statistical significance, $\alpha$, was chosen as 0.05 .

\section{RESULTS}

Both the standing and supine groups showed significant changes in strength and endurance between pre- and postintervention (Table 1). The independent sample t-test showed that there were no statistically significant differences in strength and endurance between the two groups before and after the intervention, or between the within group changes in strength and endurance (Table 2). 


\section{DISCUSSION}

This study examined the effect of cervical stabilizing exercises in the standing position and the supine position on the strength and endurance of DNM. There have been many preceding studies of cervical stabilizing exercise in the supine position. In the study done by Chiu et al., patients with chronic cervical pain did six weeks of deep flexor exercise. The results showed that the pain level and disability index of the experimental group significantly decreased, and the strength of the neck muscles significantly increased, compared to the control group ${ }^{9}$ ). Falla et al. reported that strengthening deep neck flexors reduced neck pain patients' symptoms and enhanced their ability to maintain the correct cervical vertebrae position ${ }^{10)}$. Jull et al. reported improvement in flexor strength in chronic neck pain patients who did cranio-cervical flexion exercises and cervical flexion exercises for seven weeks in order to improve the strength and endurance of their neck flexors ${ }^{11)}$. O'Leary measured $50 \%$ maximal voluntary contraction in two groups, who performed six weeks of cranio-cervical flexion exercise $(n=27)$ or cervical flexion exercise $(n=23)$, selected from 50 females with chronic mild neck pain, and reported that both groups showed significant improvements ${ }^{12)}$. Hagberg et al. reported that exercises for isometric strength and endurance for the neck and shoulders helped to reduce cervical pain and movement recovery ${ }^{13)}$. Similarly, the result of our present study showed an increase in strength and endurance of the DNM of the group which performed a cervical stabilizing exercise in the supine position $(p<0.05)$. In a similar study related to cervical stabilizing exercise in the standing position, Kjellman and Öberg conducted McKenzie exercises for three weeks for 77 patients with neck pain, and reported reduced pain intensity and Neck Disability Index ${ }^{14)}$. Wright et al. (2000) reported that temporomandibular disorder (TMD) patients, who both TMD self-management and posture training, improved TM joint and neck pain as well as trapezius and masseter pain, compared to the patients who only did TMD self-management ${ }^{8)}$. However, the chin tucks performed in this study were only used for posture training. The difference in this study was that a book was placed behind a subject's head to provide the resistance. In this study, the group with cervical stabilizing exercise in the standing position showed improvement in the strength and endurance of DNMs $(\mathrm{p}<0.05)$.

The results of the present show that there was no statistically significant difference in the strength and endurance before and after the intervention between the standing group and the supine group. However, the standing group showed a greater improvement in strength, and the supine group showed a greater improvement in endurance. This result seems to be due to the increased weight and thickness of books used by the standing group when exercising. If the thickness and weight of the books were to remains the same and the time period for one set were increased, endurance would also improve in the standing group. The results of this study show that cervical stabilizing exercises in both the standing and a supine positions, have a positive effect on the strength and endurance of DNM. For the patients who cannot perform exercises in the supine position due to time or space limitations, this study demonstrates that the exercise in the standing position could be taught so that they can easily do the exercise at school and or at work.

\section{REFERENCES}

1) Cailliet R: Soft Tissue Pain and Disability. 2nd ed. Philadelphia: F.A. Davis co, 1998.

2) Viljanen M, Malmivaara A, Uitti J, et al.: Effectiveness of dynamic muscle training, relaxation training, or ordinary activity for chronic neck pain: Randomised controlled trial. BMJ, 2003. 327: 475. [Medline] [CrossRef]

3) Ferreira PH, Ferreira ML, Maher CG, et al.: Specific stabilisation exercise for spinal and pelvic pain: A sysematic review. Aust J Physiother, 2006, 52: 79-88. [Medline] [CrossRef]

4) Gon WT, Cheung HJ, Lee KM: The effect of cervical stabilized exercise and joint mobilization on maximum muscle strength and static muscle endurance of cervical. J Korean Data Inf Sci Soc, 2010, 21: 33-42.

5) Kirkesola G: The Neurac method. Fysioterapeuten, 2009, 12: 16-25.

6) Grimmer K, Trott P: The association between cervical excursion angles and cervical short flexor muscle endurance. Aust J Physiother, 1998, 44: 201-207. [Medline]

7) Jull G, Falla D, Treleavan J, et al.: A therapeutic exercise approach for cervical disorders. In: Boyling JD, Jull G, eds. Grieve's Modern Manual Therapy, The Vertebral Coloumn. Edingburgh, UK: Churchill Livingstone, 2004.

8) Wright EF, Domenech MA, Fischer JR Jr: Usefulness of posture training for patients with temporomandibular disorders. J Am Dent Assoc, 2000, 131: 202-210. [Medline]

9) Chiu TT, Lam TH, Hedley AJ: A randomized controlled trial on the efficacy of exercise for patients with chronic neck pain. Spine, 2005, 30: 1-4. [Medline]

10) Falla D, Jull G, Hodges $P$, et al.: Andur-ance-sterngth training regime is effective in re-ducing myoelectric manifestations of cervical floxor muscle fatigue in females with chronic neck pain. Clin Neurophysiol, 2006, 117: 828-837. [Medline] [CrossRef]

11) Jull G, Falla D, Hodges P, et al.: Cervical flexor muscle retraining: physiological mechanisms of efficacy. Paper presented at 2nd international conference on movement dysfuction. Edingburgh: scotland, 2005.

12) O'Leary S, Jull G, Kim M, et al.: Specificity in retraining craniocervical flexor muscle performance. J Orthop Sports Phys Ther, 2007, 37: 3-9. [Medline] [CrossRef]

13) Hagberg M, Harms-Ringdahl K, Nisell R., et al.: Rehabilitation of neckshoulder pain in women industrial workers: a randomized endurance training with isometric shoulder strength training. Arch Phys Med Rehabil, 2000, 81: 1051-1058. [Medline] [CrossRef]

14) Kjellman G, Öberg B: A randomized clinical trial comparing general exercise, McKenzie treatment and a control group in patients with neck pain. J Rehabil Med, 2002, 34: 183-190. [Medline] [CrossRef] 